This item was submitted to Loughborough's Research Repository by the author.

Items in Figshare are protected by copyright, with all rights reserved, unless otherwise indicated.

\title{
The impact of US uncertainty on the Euro area in good and bad times: evidence from a quantile structural vector autoregressive model
}

PLEASE CITE THE PUBLISHED VERSION

https://doi.org/10.1007/s10663-018-9400-3

\section{PUBLISHER}

(C) Springer

VERSION

AM (Accepted Manuscript)

\section{PUBLISHER STATEMENT}

This work is made available according to the conditions of the Creative Commons Attribution-NonCommercialNoDerivatives 4.0 International (CC BY-NC-ND 4.0) licence. Full details of this licence are available at: https://creativecommons.org/licenses/by-nc-nd/4.0/

\section{LICENCE}

CC BY-NC-ND 4.0

\section{REPOSITORY RECORD}

Gupta, Rangan, Chi K. Lau, and Mark E. Wohar. 2019. "The Impact of US Uncertainty on the Euro Area in Good and Bad Times: Evidence from a Quantile Structural Vector Autoregressive Model”. figshare. https://hdl.handle.net/2134/33979. 


\title{
The Impact of US Uncertainty on the Euro Area in Good and Bad Times: Evidence from a Quantile Structural Vector Autoregressive Model $^{\#}$
}

\author{
Rangan Gupta*, Chi Keung Marco Lau` and Mark E. Wohar^
}

\begin{abstract}
We estimate a quantile structural vector autoregressive model for the Euro Area to assess the real effects of uncertainty shocks in expansions and recessions using monthly data covering the period of 1999:02 to 2016:05. Domestic and foreign (US) uncertainty shocks hitting during recessions are found to produce a relatively overall stronger negative impact on output growth than in expansions, with US shocks having more pronounced effects. Inflation, in general, is unaffected from a statistical perspective. Our results tend to suggest that policymakers need to implement state-dependent policies, with stimulus policies being more aggressive during recessions - something we see from our results in terms of stronger declines in the interest rate during bad times.
\end{abstract}

JEL Codes: C32, E32, E60

Keywords: Economic Policy Uncertainty, US-Euro Area Spillovers, Quantile Structural Vector Autoregressive Model

\footnotetext{
\# We would like to thank an anonymous referee for many helpful comments. However, any remaining errors are solely ours.

* Department of Economics, University of Pretoria, Pretoria, South Africa. Email: rangan.gupta@up.ac.za.

- Department of Accountancy, Finance and Economics, Huddersfield Business School, University of Huddersfield, Queensgate, HD1 3DH, UK. Email: c.lau@hud.ac.uk.

- Corresponding author. College of Business Administration, University of Nebraska at Omaha, 6708 Pine Street, Omaha, NE 68182, USA, and School of Business and Economics, Loughborough University, Leicestershire, LE11 3TU, UK. Email: mwohar@unomaha.edu.
} 


\section{The Impact of US Uncertainty on the Euro Area in Good and Bad Times: Evidence from a Quantile Structural Vector Autoregressive Model $^{\#}$}

\section{Introduction}

Following on the early works of Bernanke (1983), and Dixit and Pindyck (1994), a large body of both theoretical and empirical works have analysed the impact of uncertainty on the macroeconomy, with this line of research gaining momentum especially post the "Great Recession". ${ }^{1}$ More recently however, studies like Caggiano et al. (2014b, 2016), Foerster (2014), Schüler (2014), Jones and Enders (2016), and Balcilar et al., (2016b) have pointed out that the effect of uncertainty on the macroeconomy is state-contingent, i.e., different between recessions and expansions, with the effect being stronger during bad times. There can be several reasons behind this: (a) It is quite well-accepted that most macroeconomic variables display asymmetric behavior over the business cycle (see, for example, Caggiano and Castelnuovo (2011), Morley and Piger (2012), Abadir, et al., (2013), Morley et al., (2013)); (b) Evidence from micro and macro analyses tend to suggest countercyclicality of uncertainty with sudden increases during recessions (see for example, Bloom (2009), Bloom et al., (2014), Orlik and Veldkamp (2014), and Jurado et al., Ng (2015)). Hence uncertainty is characterized by different dynamics in expansions and recessions, and; (c) Alternative measures of uncertainty are shown to be higher and more volatile in recessions (Bloom et al., 2014). Given these empirical facts, one could expect uncertainty shocks to exert different macroeconomic effects over the business cycle (Caggiano et al., 2014b).

At this stage, it is important to highlight a specific observation that can be made from the above-mentioned studies: Barring a few exceptions, whether based on a symmetric or asymmetric approach, all the studies have primarily looked at the impact of US uncertainty on its own macroeconomic variables. Few studies that differ in this regard are those of Colombo (2013), Jones and Olson (2015), Caggiano et al., (2016), Cheng et al., (2016) ${ }^{2}$ and Stockhammar and Österholm (2016). ${ }^{3}$ These studies confirm the importance of US uncertainty relative to domestic uncertainty on other major economies like Canada, the Euro

\footnotetext{
\# We would like to thank an anonymous referee for many helpful comments. However, any remaining errors are solely ours.

${ }^{1}$ In this regard the reader is referred to the theoretical works of Bloom (2009), Fernández-Villaverde et al., (2011, 2015), Gourio (2012), Leduc and Liu (2013), Johannsen (2013), Mumtaz and Zanetti (2013), Nakata (2013), Basu and Bundick (2014), Bloom et al., (2014), Christiano et al., (2014), Floetotto et al., (2014), and Carriero et al., (2015). While the size of the impact of uncertainty on macroeconomic variables have been analysed empirically in Alexopoulos and Cohen (2009), Bachmann and Bayer (2011), Knotek II and Khan (2011), Stock and Watson (2012), Bachmann et al. (2013), Colombo (2013), Benati (2013), Jones and Olson (2013, 2015), Born and Pfeifer (2014), Alessandri and Mumtaz (2014), Caggiano et al. (2014a, b, 2016), Foerster (2014), Furlanetto et al., (2014), Gilchrist et al., (2014), Kang et al. (2014), Karnizova and Li (2014), Nodari (2014), Pellegrino (2014), Schüler (2014), Bali et al. (2015), Carriero et al. (2015), Castelnuovo et al. (2015), Gupta and Jooste (2015), Istrefi and Piloiu (2015), Jurado et al. (2015), Ludvigson et al. (2015), Mecikovsky and Meier (2015), Rossi and Sekhposyan (2015), Baker et al., (2016), Balcilar et al. (2016a, b, forthcoming), Caldara et al., (2016), Cheng et al., (2016), Jones and Enders (2016), Mumtaz et al., (2016), Rossi et al. (2016), Scotti (2016), Segnon et al. (2016), Shin and Zhong (2016), and Creal and Wu (forthcoming).

${ }^{2}$ Studies by Aastveit et al., (2017) and Balcilar et al., (forthcoming) are also somewhat related in this regard. While these studies did not directly look at the spillover effect of the uncertainty of the US economy on other major economies, they were more concerned about the domestic effectiveness of monetary policy in the wake of low and high levels of US uncertainty.

${ }^{3}$ Sin (2015) depicted significant impact of Chinese uncertainty on Taiwan and Hong Kong.
} 
area, Japan, Sweden and the UK. ${ }^{4}$ Against this backdrop of limited international evidence of the asymmetric impact of uncertainty, we aim to investigate whether the impact of both domestic and US uncertainty on measures of output, prices and interest rates is different across expansions and recessions for the Euro area, given that European Union is the largest trading partner of the US. For our purpose, we use a quantile structural vector autoregressive (QSVAR) framework applied on monthly data covering the period of February, 1999 to May, 2016 for the Euro area. By conditioning our analysis on various quantiles of the measure of output, we are able to capture the impact of uncertainty shocks based on impulse response functions for the key macroeconomic variables at these regimes, with lower quantiles capturing recessionary periods, and higher quantiles indicative of expansions. ${ }^{5}$ Note that, our sample period includes the zero-lower bound (ZLB) situation in the Euro area; but by using shadow policy rates obtained from the three-factor shadow rate term structure model (SRTSM) of Wu and Xia (2016), we are also able to study the impact of uncertainty on monetary policy behaviour across recessions and expansions without worrying about explicitly modelling the ZLB. Wu and Xia (2016) show that such a model offers an excellent description of the historic interest rate behaviour and can be used to summarize the macroeconomic effects of both conventional and unconventional monetary policies. ${ }^{6}$ This way, we are different from many studies in the literature discussed above on macroeconomic effects of uncertainty, since these analyses curtail their sample period to before the ZLB, and hence, only presents an incomplete picture especially in terms of monetary policy.

Note that, our decision to use the QSVAR as in Schüler (2014) over the generally used smooth transition (Caggiano et al., 2014b, 2016; Jones and Enders, 2016) or Markovswitching (Balcilar et al., (2016b)) approaches to model the asymmetric effect of uncertainty is motivated out of the advantages the QVAR approach possesses over other nonlinear models. As described in Linnemann and Winkler (2016), quantile models do not rely on: (a) An ex ante classification of different regimes, like recessions and expansions in Markovswitching models $;^{7}$ and (b) Specification of a parametric transition function that determines the regime in which the economy resides. By contrast, the QSVAR used here allow us to estimate the impact of uncertainty shocks on the whole conditional distribution of output with

\footnotetext{
${ }^{4}$ In this regard, it must be mentioned that Cheng et al., (2016) analysed the impact of US partisan conflict, besides US uncertainty, on the Euro area macroeconomic variables, and showed that partisan conflict has a relatively stronger effect than economic uncertainty. In addition, Jones and Olson (2015) were concerned more with the impact of financial market uncertainty of the US economy on Japan and the UK, and not necessarily the spillover of aggregate macroeconomic uncertainty like what we do in this paper (see below in the data segment for details on our measure of uncertainty), or what Colombo (2013), Caggiano et al., (2016), Cheng et al., (2016), and Stockhammar and Österholm (2016) did.

${ }^{5}$ While here we concentrate only on the Euro area, our results based on QSVAR models for the US and UK confirm the findings of the earlier studies on the asymmetric effect of uncertainty; i.e., domestic uncertainty has a relatively stronger influence during recessions than expansions. For the UK, US uncertainty also shows an asymmetric impact. Complete details of these results are available upon request from the authors.

${ }^{6}$ Note that shadow interest rate data is also available for Japan based on the work of Krippner (2012, 2013), who in turn derives these rates based on a two-factor model for also the Euro area, UK and US. However, Wu and Xia (2016) indicate that the three-factor term structure model fits the data better than the corresponding model with two factors. Hence, we decided to leave Japan out, as Wu and Xia (2016) does not provide estimates for the shadow rate of Japan. So in this paper, we concentrate formally on the Euro area, and also the UK and US, with results of the latter two countries not reported explicitly in the paper, but available upon request from the authors.

7 Though it does not hold in our case, since we only have one economic activity variable, namely output, quantiles of which we condition our analysis on; but in a QSVAR, in the presence of more than one variable capturing economic activity, multiple variables can be simultaneously used as a measure of business cycle indicators. This, however, is not a possibility in other parametric nonlinear models, where we need to specify a particular variable as an indicator of business cycle.
} 
parameters being allowed to vary across different quantiles without constraints. Moreover, the nonlinear effects analyzed here do not require us to make a call on potentially difficult issues associated with the timing of business cycles and precise definition of expansions and recessions. In other words, the QSVAR is a general approach that allows us to capture the potential nonlinear effects of uncertainty which cannot be described as differences due to the economy being in one of many possible discrete numbers of regimes. However, quantile methods also have some disadvantages relative to the Markov-switching of smooth transition function-based models. For instance, a QSVAR does not provide an explicit and testable model of the functional form of the nonlinearities in the data. The estimated quantile specific effects of uncertainty may also be difficult to use for policy makers, as basing policy decisions on quantiles would require exact knowledge about the conditional quantile of economic activity that the economy is at the time of the policy decision. But, one could also argue that policy makers usually have reasonable estimates of whether economic activity is in the lower or upper parts of its conditional distribution, given that output is likely to be in the lower half of its conditional distribution if it is below the mean forecast that policy makers regularly produce. In sum, there exists a trade-off between the ability of quantile methods to capture nonlinearities in a relatively unrestricted way against the specific formulation of the parametric nonlinear models. But given that, our limited knowledge of the precise nature and origins of the nonlinear effects of uncertainty, we decided to use the QVAR approach in this paper. To the best of our knowledge, this is the first paper to analyze the asymmetric impact of domestic and US uncertainty on macroeconomic variables of the Euro area using a QSVAR model. ${ }^{8}$ The only other paper that is somewhat related to our work is that by Caggiano et al., (2016), where the authors use a smooth transition VAR to analyse the impact of US uncertainty on Canada contingent on recessions and expansions of the former. The authors find strong evidence in favor of spillover effects in recessions. However, Canada turns out to be economically resilient to U.S. uncertainty shocks during expansions. But note, unlike Caggiano et al., (2016), we condition our analysis on the recessions and expansions of the domestic economy while analyzing the impact of own uncertainty and spillover of US uncertainty on macroeconomic variables of the Euro area. The remainder of the paper is organized as follows: Section 2 presents the description of the data, as it helps in discussing our model and econometric methodology in Section 3. Section 4 is devoted to the empirical results, with Section 5 concluding the paper.

\section{Data}

Our dataset for the Euro area comprises of two measures of uncertainty: domestic and that of the US economy, industrial production, consumer price index (CPI), and the policy rate at monthly frequency over the period of 1999:01 to 2016:05, with the start and end dates being purely driven by data availability of the variables considered. The data on industrial production and CPI comes from the main economic indicators (MEIs) database of the Organisation for Economic Co-operation and Development (OECD), while the policy rates, which in turn, are the estimated shadow rates derived from a three-factor shadow rate term structure model (SRTSM) of Wu and Xia (2016) is available for download from the website of Jing Cynthia Wu at: https://sites.google.com/site/jingcynthiawu/home/wu-xia-shadowrates. Note however, that the shadow rates only starts from 2004:09, so for the period 199:01

\footnotetext{
${ }^{8}$ Chuliá et al. (2017) used bivariate QSVAR models to analyze the impact of domestic and US uncertainty on equity markets of both mature and emerging countries.
} 
to 2004:08, we use the short-term interest rate obtained from main economic indicators database of the OECD.

Uncertainty is a latent variable, and two approaches have been used primarily in measuring uncertainty, besides the implied volatility indices associated with financial markets (see Strobel (2015) for a detailed discussion on alternative measures of uncertainty): (1) The news-based approach of Brogaard and Detzel (2015) and Baker et al. (2016), whereby the authors perform month-by-month searches of newspapers for terms related to economic and policy uncertainty to construct their measure of economic policy uncertainty (EPU); ${ }^{9}$ (ii) Alternatively, Mumtaz and Zanetti (2013), Mumtaz and Surico (2013), Alessandri and Mumtaz (2014), Mumtaz and Theodoridis (2015, 2016), Bali et al. (2015), Carriero et al. (2015), Chuliá et al. (2015), Jurado et al. (2015), Ludvigson et al. (2015), Rossi and Sekhposyan (2015), Mumtaz et al., (2016), Rossi et al. (2016), Scotti (2016), Shin and Zhong (2016), Creal and Wu (forthcoming) recover measures of uncertainty from the estimation of various types of small- and large-scale structural models related to macroeconomics and finance. Though both these approaches are equally popular in the literature, we take the news-based route following the two studies (Colombo (2013) and Cheng et al., (2016)) on international spillover of US uncertainty on the Euro area. Our decision to go with the newsbased measure of uncertainty is also motivated by the fact that data on EPU for the economies of our concern (and also other countries) are available freely for download from: www.policyuncertainty.com, and hence, does not require any complicated estimation of a structural model to generate it in the first place, with the measure of uncertainty being contingent on the variables included in the model. ${ }^{10}$

With the QSVAR approach requiring mean reverting data, we transform the industrial production into its growth rate and CPI to month-on-month inflation; while natural logarithmic transformation is taken for the domestic and foreign EPUs, and the shadow rates are retained as untransformed. Our effective sample starts from 1997:02 and 1999:02 due to the transformation to output and CPI.

\section{Methodology}

As indicated earlier, this paper uses a quantile structural vector autoregressive (QSVAR) model to estimate quantile impulse responses of output growth, inflation and interest rate of the Euro area (EA) following a shock to the domestic EPU, and also the impact on not only the three key variables, but also its EPU given a shock to the US EPU. We are interested in examining these dynamic responses by conditioning on various quantiles of the growth of industrial production that allows us to capture the various phases of the Euro area business cycle.

We start off by laying the basics of a quantile regression. We specify the $\tau$-th quantile $(0<\tau$ $<1)$ of the conditional distribution of the vector of dependent variables $y_{t}$ given a vector of independent variables $x_{t}$, as follows:

\footnotetext{
${ }^{9}$ Azzimonti (2015), Caldara and Iacoviello (2016), and Manela and Moreira (forthcoming) use similar newsbased approach to come up with measures on partisan conflict, geopolitical risks and news implied volatility (NVIX).

10 Further details on the EPU measure for the US can be found here: http://www.policyuncertainty.com/us_monthly.html, while that of the Euro area is available here: http://www.policyuncertainty.com/europe_monthly.html.
} 
$Q_{\tau}\left(y_{t} \mid x_{t}\right)=x_{t} \beta(\tau)$

where $Q_{\tau}\left(y_{t}\right)=F^{-1}(\tau), F\left(y_{t}\right)$ is the probability distribution function (pdf) of the $y_{t}$. The parameter vector of $\beta(\tau)$ quantifies the responses of variables at different quantile $\tau$ of the distribution.

Parameters in equation (1) can be estimated by minimizing the absolute value of the residual using the following objective function:

$Q_{\tau}\left(\beta_{\tau}\right)=\underset{\beta(\tau)}{\operatorname{argmin}} \sum_{i=1}^{T}\left(\tau-1_{\left\{y_{t}<x_{t} \beta(\tau)\right\}}\right)\left|y_{t}-x_{t} \beta(\tau)\right|$

where $1_{\left\{y_{t}<x_{t} \beta(\tau)\right\}}$ is the indicator function, with the solution to the quantile regression model being obtained using the programming algorithm suggested by Koenker and d'Orey (1987).

Building on the quantile regression framework in Eq. (1), we can specify the reduced form VAR of the Euro area economy for $\tau^{\text {th }}$ quantile as follows, where the predictors are now lagged values of all the endogenous variables of the model:

$y_{t}=c(\tau)+\sum_{i=1}^{p} \mathrm{~B}_{i}(\tau) y_{t-i}+\mu_{t}(\tau) \quad$ for $t=1, \ldots, T$

where

$y_{t}=\left[\begin{array}{c}E P U_{U S A} \\ \text { INFLAT } \\ \text { IPG } \\ I N T E R E S T \\ \text { EPU }\end{array}\right] \quad c(\tau)=\left[\begin{array}{c}c_{1}\left(\tau_{1}\right) \\ c_{2}\left(\tau_{2}\right) \\ c_{3}\left(\tau_{3}\right) \\ c_{4}\left(\tau_{4}\right) \\ c_{5}\left(\tau_{5}\right)\end{array}\right] \quad \mu_{t}(\tau)=\left[\begin{array}{c}\mu_{t}^{E P U_{U S A}}\left(\tau_{1}\right) \\ \mu_{t}^{\mathrm{INFLAT}}\left(\tau_{2}\right) \\ \mu_{t}^{\mathrm{IPG}}\left(\tau_{3}\right) \\ \mu_{t}^{I N T E R E S T}\left(\tau_{4}\right) \\ \mu_{t}^{E P U}\left(\tau_{5}\right)\end{array}\right]$

$B_{i}(\tau)=\left(\begin{array}{lllll}B_{i, 11}\left(\tau_{1}\right) & B_{i, 12}\left(\tau_{1}\right) & B_{i, 13}\left(\tau_{1}\right) & B_{i, 14}\left(\tau_{1}\right) & B_{i, 15}\left(\tau_{1}\right) \\ B_{i, 21}\left(\tau_{2}\right) & B_{i, 22}\left(\tau_{2}\right) & B_{i, 23}\left(\tau_{2}\right) & B_{i, 24}\left(\tau_{2}\right) & B_{i, 25}\left(\tau_{2}\right) \\ B_{i, 31}\left(\tau_{3}\right) & B_{i, 32}\left(\tau_{3}\right) & B_{i, 33}\left(\tau_{3}\right) & B_{i, 34}\left(\tau_{3}\right) & \left.B_{i, 35}\left(\tau_{3}\right)\right) \\ B_{i, 41}\left(\tau_{4}\right) & B_{i, 42}\left(\tau_{4}\right) & B_{i, 43}\left(\tau_{4}\right) & B_{i, 44}\left(\tau_{4}\right) & B_{i, 45}\left(\tau_{4}\right) \\ B_{i, 51}\left(\tau_{5}\right) & B_{i, 52}\left(\tau_{5}\right) & B_{i, 53}\left(\tau_{5}\right) & B_{i, 54}\left(\tau_{5}\right) & B_{i, 55}\left(\tau_{5}\right)\end{array}\right)$

where $y_{t}$ is a $5 \times 1$ vector of endogenous variables containing the US economic policy uncertainty index (EPUUSA), inflation rate (INFLAT) industrial production growth (IPG), the shadow policy rate (INTEREST), and the Euro area economic policy uncertainty index (EPU). $\mathrm{c}(\tau)$ is an intercept vector with quantiles $\tau=\left(\tau_{1}, \tau_{2}, \tau_{3}, \tau_{4}, \tau_{5}\right), \mathrm{B}_{\mathrm{i}}(\tau)$ represents a $5 \times 5$ lagged coefficient matrix with quantiles $\tau=\left(\tau_{1}, \tau_{2}, \tau_{3}, \tau_{4}, \tau_{5}\right)$ with $i=1, \ldots, \rho$, and the error terms with quantiles $\tau=\left(\tau_{1}, \tau_{2}, \tau_{3}, \tau_{4}, \tau_{5}\right)$ is denoted by a $5 \times 1$ vector of $\mu_{t}(\tau)$.

In our study we use the above model to examine the effect of domestic and US EPU on the variables of the Euro area, conditional on the various quantiles of the industrial production growth rate capturing various phases of the domestic economy business cycle. Assuming that the error terms $\mu_{\mathrm{t}}(\tau)$ obeys the restrictions of:

$$
Q_{\tau}\left(\mu_{t}(\tau) \mid y_{t-1, \cdots,} y_{t-p}\right)=0
$$

Combining Eq. (3) and Eq. (4) we obtain the population responses of y at quantiles $\tau=\left(\tau_{1}, \tau_{2}\right.$, $\left.\tau_{3}, \tau_{4}, \tau_{5}\right)$ such that: 
$Q_{\tau}\left(\mu_{t}(\tau) \mid y_{t-1, \ldots,} y_{t-p}\right)=c(\tau)+\sum_{i=1}^{p} \mathrm{~B}_{i}(\tau) y_{t-i}$

We can estimate Eq. (5) for each quantile $\tau$ using the quantile regression approach of Cecchetti and Li (2008). Following the decomposition procedure of Kilian and Park (2009), we can identify the shocks of the economic variables by imposing structural restrictions on the error term $\mu_{\mathrm{t}}(\tau)$, so that:

$$
\begin{aligned}
& \mu_{t}(\tau)=\left[\begin{array}{c}
\mu_{t}^{E P U_{U S A}}\left(\tau_{1}\right) \\
\mu_{t}^{\mathrm{INFLAT}}\left(\tau_{2}\right) \\
\mu_{t}^{\mathrm{IPG}}\left(\tau_{3}\right) \\
\mu_{t}^{I N T E R E S T}\left(\tau_{4}\right) \\
\mu_{t}^{E P U}\left(\tau_{5}\right)
\end{array}\right]=\left[\begin{array}{ccccc}
a_{11}\left(\tau_{1}\right) & 0 & 0 & 0 & 0 \\
a_{21}\left(\tau_{2}\right) & a_{22}\left(\tau_{2}\right) & 0 & 0 & 0 \\
a_{31}\left(\tau_{3}\right) & a_{32}\left(\tau_{3}\right) & a_{33}\left(\tau_{3}\right) & 0 & 0 \\
a_{41}\left(\tau_{4}\right) & a_{42}\left(\tau_{4}\right) & a_{43}\left(\tau_{4}\right) & a_{44}\left(\tau_{4}\right) & 0 \\
a_{51}\left(\tau_{5}\right) & a_{52}\left(\tau_{5}\right) & a_{53}\left(\tau_{5}\right) & a_{54}\left(\tau_{5}\right) & a_{55}\left(\tau_{5}\right)
\end{array}\right] \\
& {\left[\begin{array}{c}
\epsilon_{t}^{\text {EPU USA }}{ }^{\text {Shock }}\left(\tau_{1}\right) \\
\epsilon_{t}^{\text {INFLATshock }}\left(\tau_{2}\right) \\
\epsilon_{t}^{\text {IPGShock }}\left(\tau_{3}\right) \\
\epsilon_{t}^{\text {INTERESTShock }}\left(\tau_{4}\right) \\
\epsilon_{t}^{\text {EPUShock }}\left(\tau_{5}\right)
\end{array}\right]}
\end{aligned}
$$

We assume the $\epsilon_{t}$ is a white noise process, and employ a standard Cholesky decomposition by imposing a lower triangular matrix as in Colombo (2013). The ordering of the uncertainty (foreign and domestic) is of importance here, with us assuming that shocks hitting the US EPU has a contemporaneous impact on Euro area variables, while US EPU is only affected with a delay due to movements in the Euro area. While the domestic uncertainty is ordered last to purge the uncertainty measure of contemporaneous movements of the macroeconomic indicators (output growth, inflation and the policy rate), and in the process sharpen the identification of the uncertainty shocks (Colombo, 2013). ${ }^{11}$

Once we orthogonalize the covariance matrix of the residuals in Eq. (6) using a Cholesky decomposition, we can calculate the associated quantile-specific impulse response function, and obtain the 95 percent confidence interval by using a 'bootstrapping' approach (replicated 5000 times) which involves resampling from the estimated residuals. The reader is referred to Linnemann and Winkler (2016) for further details. We aim to use the impulse response analysis to plot the impact of one standard deviation increase in innovation of the domestic and US EPUs at time $t$ on another variable at time $t+s$, by conditioning the impulse response functions on various quantiles ( $\tau=0.25$ (recessionary phase), 0.5 (normal phase) and 0.75 (expansionary phase)) of the industrial production growth. The optimal lag order in QSVAR model is selected by the Akaike information criterion (AIC), with the lag-lengths being 6,6 and 4 at $\tau=0.25,0.5$ and 0.75 respectively.

\footnotetext{
${ }^{11}$ Based on the suggestion of an anonymous referee, we also ordered the Euro area EPU after the US EPU. Given this ordering of the variables, our results were both qualitatively and quantitatively similar (barring the first period for inflation, industrial production growth and interest rate) to those reported below following a shock to the domestic EPU. Complete details of these results are available upon request from the authors.
} 


\section{Results}

We start off by analyzing the impact of an increase of one standard deviation of domestic, i.e., Euro area, uncertainty on its macroeconomic variables. For the sake of comparability, in Figure 1, we present the impulse responses (from the point of impact to tenmonth-ahead, i.e., a total of 11 periods) for each of the variables of concern simultaneously for $\tau=0.25$, 0.5 and 0.75 , with the quantiles being conditioned on output growth. As can be seen, an increase in EPU, leads to a decline in output growth, with the effect being strongest at $\tau=0.25$, i.e., during the recessionary phase over the entire horizon. But interestingly, the initial decline in output growth is the highest under $\tau=0.5$, and is about 0.14 percent. Inflation initially increases, but then declines, with the fall being the highest again during the recession for the overall horizons considered, with the initial impact being strongest when the output growth is conditioned on its median value. There is also a negative impact on interest rate, with the effects being quite similar for $\tau=0.5$ and 0.75 , but the decline is slightly bigger at $\tau=0.25$. While, output seems to recover from the second month onwards, the behavior of the inflation and the interest rates are quite persistent. ${ }^{12}$ Note that, US EPU also increases following a shock to Euro area EPU ${ }^{13}$ but the size of the impact is indistinguishable across the quantiles. In general, the pattern of obtained results are in line with Colombo (2013), and make sense intuitively, with them suggesting that that increase in uncertainty possibly leads households to postpone their consumption due to a precautionary saving-motive, and firms to delay investment decisions due to an increase in the option-value of waiting. The fall in output growth and inflation is an indication that uncertainty shocks are aggregate demand in nature (see for example, Bloom, 2009; Colombo, 2013; Jones and Olson, 2015; Baker et al., 2016 in this regard). The monetary policy easing is an indication of the monetary authority making an attempt to recover the economy from the negative impact of an uncertainty shock on output, and is also consistent with an inflation-targeting strategy.

\section{[INSERT FIGURE 1]}

In Figure 2, we present the impulse response function for an increase in the US EPU. Again, as with domestic EPU shocks, the decline of output growth (by about 0.23 percent), inflation and the interest rates of the Euro area are stronger when the economy is in recession. However, unlike the domestic EPU shock, the initial impact on output and inflation is also strongest during recessions and not for $\tau=0.5$. Note that, Figure A1 in the Appendix presents the results separately for each variable across these three quantiles with the confidence bands. Given this, as can be seen from Figure A1, impact of a significant US EPU shock is significant for output growth, interest rate and the Euro area EPU ${ }^{14}$, but not the inflation rate. When we compare across Figures 1 and 2, we observe that the impact of foreign EPU is stronger than domestic EPU especially in the recessionary phase. ${ }^{15}$ While US EPU increases

\footnotetext{
12 When we looked at confidence bands, we observed that the impacts are statistically significant only for output and interest rates, but not the inflation, following a statistically significant increase in the domestic EPU.

${ }^{13}$ When we looked at the confidence bands, this effect was statistically significant.

${ }^{14}$ Spillovers of EPU across countries have been studied by various papers in detail (see, Gupta et al., (2016) for a detailed literature review in this regard).

${ }^{15}$ A variance decomposition analysis showed that the cumulative effect (over horizons 0 to 10 -month-ahead) of US EPU on output growth at $\tau=0.25,0.50$ and 0.75 is 14.65 percent, 13.40 percent, and 13.63 percent respectively, which were consistently higher (especially at $\tau=0.25$ ) when we compared to the corresponding values of 3.20 percent, 13.07 percent and 9.87 percent respectively following a shock to the domestic EPU. These results, complete details of which are available upon request from the authors, basically confirm the finding from the impulse response analyses.
} 
the EPU of the Euro area significantly, the changes are indistinguishable across the various quantiles. ${ }^{16,17}$

\section{[INSERT FIGURE 2]}

In sum, our results show a hump-shaped impulse response for output growth following an increase in uncertainty, with the lowest point of hump being more severe during periods of recessions. The nature of this response is qualitatively in line with the prediction by the general equilibrium model of household's consumption/savings decisions developed by Bloom et al. (2014), which in turn, calls for consumption smoothing in equilibrium. With consumption smoothing being more difficult to implement in recessions due to harsher financial conditions and less accessible financial markets, it is expected that the effect of a positive uncertainty shock would be stronger during recessionary periods relative to expansions. Following Blanchard (2009), from a policy perspective, our results tend to suggest that policymakers need to implement state-dependent policies, which are aimed at removing tail risks, channel funds towards the private sector, and undo the "wait-and-see" attitudes by creating incentives to spend more strongly during periods of recession following an uncertainty shock, i.e., stimulus policies should be more aggressive during recessions something we see from our results in terms of stronger declines in the interest rate.

\section{Conclusion}

Following the "Great Recession", a growing number of studies have analysed the macroeconomic impact of uncertainty shocks. However, this literature has primarily dealt with the US economy, barring a few exceptions. In addition, more recently, some of the papers have also looked at the possible asymmetric impact of uncertainty across expansions and recessions. Against this backdrop, we investigate whether impact of both domestic and US uncertainty on Euro area output, prices and interest rates, is different across expansions and recessions. For our purpose, we use a quantile structural vector autoregressive (QSVAR) framework applied on monthly data covering the period of February, 1999 to May, 2016. By conditioning our analysis on various quantiles of the measure of output, we are able to capture the impact of uncertainty shocks based on impulse response functions for the key macroeconomic variables at these regimes, with lower quantiles capturing recessionary periods, and higher quantiles indicative of expansions. We find that both domestic and US uncertainty shocks hitting during recessions produce a relatively stronger negative impact on output growth than in expansions, with the effect being stronger following a shock to the US EPU. A hump-shaped response of output growth is qualitatively in line with the prediction by the general equilibrium model of Bloom et al. (2014), which in turn, calls for consumption smoothing in equilibrium. With a stronger expansionary monetary policy during recessions,

\footnotetext{
${ }^{16}$ Our results are qualitatively similar if we use $\tau=0.1$ and 0.9 to characterize the recessionary and expansionary regimes respectively. Complete details of these results are available upon request from the authors.

17 Based on the suggestions of an anonymous referee, we conducted two additional robustness checks: (a) First, we included the shadow rate of the US (derived from Wu and Xia (2016)) and ordered it before the US EPU, and; (b) Second, we included changes in net exports (as it was non-stationary in levels) of the Euro area (derived from the OECD's MEIs database) and ordered it before the domestic EPU. Under (b), results were qualitatively and quantitatively the same, as a shock to US EPU failed to have a statistically significant impact on changes in net exports (though it was positive), while under (a), our results were qualitatively similar, but the severity of the effects were marginally reduced, since an increase in US EPU, resulted in a statistically significant decline in the US shadow rate, thus nullifying to some extent the negative influence of the US EPU shock on the Euro area variables. Complete details of these results are available upon request from the authors.
} 
our results tend to suggest that policymakers implement state-dependent policies and stimulus policies are more aggressive during bad times.

As part of future research, it would also be interesting to analyze whether the impact of increases or decreases in uncertainty tends to have an asymmetric impact on macro variables of the Euro area, along the lines of Foerster (2014), and Jones and Enders (2016). In this regard, one could also conduct various types of asymmetry analysis of uncertainty effects (i.e., whether the effects are contingent on the state of the economy and/or increases and decreases in uncertainty tend to have varied impacts) for not only the Euro area, but also other developed and emerging markets, given that news-based measures of uncertainty, developed by Baker et al., (2016), is available for many other countries besides the US and Euro area. Further, it is also possible to use the QSVAR framework to analyze the impact of domestic and foreign uncertainty on the effectiveness of monetary policy of a specific country (as in Caggiano et al., (2014b), Aastveit et al., (2017) and Balcilar et al., (forthcoming)) by conditioning the analysis on the various quantiles of the measure of uncertainty. Finally, by conditioning the interest rate at upper and lower quantiles, one could also analyze the similarities and differences in the monetary transmission mechanism during unconventional and conventional monetary policy stances of the central banks, given the ZLB situation post the "Great Recession”. 


\section{References}

Aastveit, K. A., G. J. Natvik, and S. Sola (2017). Macroeconomic Uncertainty and the Effectiveness of Monetary Policy. Journal of International Money and Finance 76, 50-67.

Abadir, K., G. Caggiano, and G. Talmain (2013). Nelson-Plosser revisited: the ACF approach. Journal of Econometrics, 175, 22-34.

Alessandri, P. and H. Mumtaz (2014). Financial regimes and uncertainty shocks. School of Economics and Finance, Queen Mary University of London Working Paper No.729.

Alexopoulos, M., and J. Cohen (2009). Uncertain Times, Uncertain Measures.University of Toronto, Department of Economics Working Paper No. 325.

Azzimonti, M. (2015). Partisan Conflict and Private Investment. NBER Working Paper No. w21273.

Bachmann, R. and C. Bayer (2011). Uncertainty business cycles-really? National Bureau of Economic Research Working Paper No. w16862.

Bachmann, R., S. Elstner, and E. Sims (2013). Uncertainty and economic activity: Evidence from business survey data. American Economic Journal: Macroeconomics 5, 217-249.

Baker, S., N. Bloom, and S. Davis (2016). Measuring economic policy uncertainty. The Quarterly Journal of Economics, doi: 10.1093/qje/qjw024.

Balcilar, M., Demirer, R., Gupta, R., and van Eyden, R. (Forthcoming). Effectiveness of Monetary Policy in the Euro Area: The Role of US Economic Policy Uncertainty. Journal of Policy Modeling.

Balcilar, M., Gupta, R., and Jooste, C. (2016a). Long memory, economic policy uncertainty and forecasting US inflation: a Bayesian VARFIMA approach. Applied Economics, http://dx.doi.org/10.1080/00036846.2016.1210777.

Balcilar, M., Gupta, R., and Segnon, M. (2016b). The Role of Economic Policy Uncertainty in Predicting U.S. Recessions: A Mixed-frequency Markov-switching Vector Autoregressive Approach. Economics: The Open-Access, Open-Assessment E-Journal, 10 (2016-27): 1—20.

Bali, T. G., S. J. Brown, and Y. Tang (2015). Macroeconomic uncertainty and expected stock returns. Georgetown McDonough School of Business Research Paper No. 2407279.

Basu, S., and B. Bundick (2014). Uncertainty Shocks in a Model of Effective Demand. Federal Reserve Bank of Kansas City Research Working Paper No. 14-15.

Benati, L. (2013). Economic policy uncertainty and the great recession. Mimeo, University of Bern.

Bernanke, B. S. (1983). Irreversibility, uncertainty, and cyclical investment. The Quarterly Journal of Economics 98, 85-106. 
Blanchard, O. (2009). (Nearly) nothing to fear but fear itself. The Economist, Economics focus (guest article), January 29.

Bloom, N. (2009). The Impact of Uncertainty Shocks. Econometrica, 77(3), 623. 685.

Bloom, N., M. Floetotto, N. Jaimovich, I. Saporta-Eksten, and S. J. Terry (2014). Really Uncertain Business Cycles. Stanford University, mimeo.

Born, B., and J. Pfeifer (2014). Policy Risk and the Business Cycle. Journal of Monetary Economics, 68, 68-85.

Brogaard, J. and A. Detzel (2015). The asset-pricing implications of government economic policy uncertainty. Management Science 61, 3-18.

Caggiano, G., and E. Castelnuovo (2011). On the Dynamics of International Inflation. Economics Letters, 112(2), 189-191.

Caggiano, G., E. Castelnuovo, and N. Groshenny (2014a). Uncertainty shocks and unemployment dynamics in US recessions. Journal of Monetary Economics 67, 78-92.

Caggiano, G., E. Castelnuovo, and G. Nodari (2014b). Uncertainty and monetary policy in good and bad times. Dipartimento di Scienze Economiche "Marco Fanno", Working Paper No. 0188.

Caggiano, G., Castelnuovo, E., and Figueres, J.M. (2016). Economic Policy Uncertainty Spillovers in Booms and Busts, Mimeo, University of Padova and University of Melbourne.

Caldara, D., and Iacoviello, M. (2016). Measuring Geopolitical Risk. Working Paper, Board of Governors of the Federal Reserve Board.

Carriero, A., Mumtaz, H., Theophilopoulou, A., and Theodoridis, K. (2015). The Impact of Uncertainty Shocks under Measurement Error: A Proxy SVAR Approach. Journal of Money, Credit and Banking, 47(6), 1223-1238.

Castelnuovo, E., G. Caggiano, and G. Pellegrino (2015). Estimating the real effects of uncertainty shocks at the zero lower bound. Dipartimento di Scienze Economiche "Marco Fanno", Working Paper No. 0200.

Cecchetti, S. and Li, H. (2008). Measuring the Impact of Asset Price Booms Using Quantile Vector Autoregressions, Brandeis University, Department of Economics, Mimeo.

Cheng, C.-H. J., W. A. Hankins, and C.-W. J. Chiu (2016). Does US partisan conflict matter for the Euro area? Economics Letters 138, 64-67.

Christiano, L., R. Motto, and M. Rostagno (2014). Risk Shocks. American Economic Review, 104(1), 27-65.

Chuliá, H., Gupta, R., Uribe, J. M., and M.E. Wohar (2017). Impact of US uncertainties on emerging and mature markets: Evidence from a quantile-vector autoregressive approach. Journal of International Financial Markets, Institutions and Money, 48: 178-191. 
Colombo, V. (2013). Economic policy uncertainty in the US: Does it matter for the Euro area? Economics Letters 121, 39-42.

Creal, D. D. and C. Wu (Forthcoming). Monetary policy uncertainty and economic fluctuations. International Economic Review.

Dixit, A. K. and R. S. Pindyck (1994). Investment under uncertainty. Princeton University Press.

Fernández-Villaverde, J., P. Guerrón-Quintana, J. F. Rubio-Ramírez, and M. Uribe (2011). Risk Matters: The Real Effects of Volatility Shocks. American Economic Review, 101, 25302561.

Fernández-Villaverde, J., P. Guerrón-Quintana, K. Kuester, and J. F. Rubio-Ramírez (2015). Fiscal Volatility Shocks and Economic Activity. American Economic Review, 105(11), 3352-3384.

Foerster, A. (2014). The Asymmetric Effects of Uncertainty on Employment. Federal Reserve Bank of Kansas City, Economic Review, Quarter 3, 5-26.

Furlanetto, F., F. Ravazzolo, and S. Sarferaz (2014). Identification of financial factors in economic fluctuations. Norges Bank Working Paper No. 09/2014.

Gilchrist, S., J. W. Sim, and E. Zakrajek (2013). Uncertainty, Financial Frictions, and Irreversible Investment. Divisions of Research \& Statistics and Monetary Affairs, Federal Reserve Board, Finance and Economics Discussion Series, Paper No. 2014-69.

Gourio, F. (2012). Disaster Risk and Business Cycles. American Economic Review, 102(6), 2734-2766.

Gupta, R., and C. Jooste (Forthcoming). Unconventional Monetary Policy Shocks in OECD Countries: How Important is the Extent of Policy Uncertainty? International Economics and Economic Policy.

Gupta, R., Pierdzioch, C., and M. Risse (2016). On international uncertainty links: BARTbased empirical evidence for Canada. Economics Letters, 143, 24-27.

Istrefi, K., and A. Piloiu (2015). Economic Policy Uncertainty and Inflation Expectations, Banque de France, mimeo.

Johannsen, B. K. (2013). When are the Effects of Fiscal Policy Uncertainty Large? Northwestern University, mimeo.

Jones, P. M. and E. Olson (2013). The time-varying correlation between uncertainty, output and inflation: Evidence from a DCC-GARCH model. Economics Letters 118, 33-37.

Jones, P. M., and Enders, W. (2016). The Asymmetric Effects of Uncertainty on Macroeconomic Activity. Macroeconomic Dynamics, 20(5), 1219-1246 
Jones, P. M., and Olson, E. (2015). The International Effects of US Uncertainty. International Journal of Finance \& Economics, 20, 242-252.

Jurado, K., S. C. Ludvigson, and S. Ng (2015). Measuring Uncertainty. American Economic Review, 105(3), 1177-1216.

Kang, W., K. Lee, and R. A. Ratti (2014). Economic policy uncertainty and firm-level investment. Journal of Macroeconomics 39, 42-53.

Karnizova, L. and J. C. Li (2014). Economic policy uncertainty, financial markets and probability of US recessions. Economics Letters 125, 261-265.

Kilian, L. and Park, C. (2009). The impact of oil price shocks on the US stock market. International Economic Review, 50, 1267-1287.

Knotek II, E. S. and S. Khan (2011). How do households respond to uncertainty shocks. Federal Reserve Bank of Kansas City Economic Review 96, 5-34.

Koenker, R. W., and d'Orey, V. (1987). Algorithm AS 229: Computing regression quantiles. Journal of the Royal Statistical Society. Series C (Applied Statistics), 36(3), 383-393.

Krippner, Leo. (2012). Modifying Gaussian Term Structure Models When Interest Rates are Near the Zero Lower Bound. Reserve Bank of New Zealand Discussion Paper 2012/02.

Krippner, Leo. (2013). A Tractable Framework for Zero Lower Bound Gaussian Term Structure Models. Australian National University CAMA Working Paper 49/2013.

Leduc, S., and Z. Liu (2013). Uncertainty Shocks are Aggregate Demand Shocks. Federal Reserve Bank of San Francisco, Working Paper 2012-10.

Ludger Linnemann, L., and Winkler, R. (2016). Estimating nonlinear effects of fiscal policy using quantile regression methods. Oxford Economic Papers. doi: 10.1093/oep/gpw020.

Ludvigson, S. C., S. Ma, and S. Ng (2015). Uncertainty and business cycles: Exogenous impulse or endogenous response? National Bureau of Economic Research, Working Paper No. w21803.

Manela, A., and Moira A. (Forthcoming). News Implied Volatility and Disaster Concerns, Journal of Financial Economics.

Mecikovsky, A. M., and M. Meier (2015). Do plants freeze upon uncertainty shocks? University of Bonn, mimeo.

Morley, J., and J. Piger (2012). The Asymmetric Business Cycle. Review of Economics and Statistics, 94(1), 208-221.

Morley, J., J. Piger, and P.-L. Tien (2013). Reproducing Business Cycle Features: Are Nonlinear Dynamics a Proxy for Multivariate Information? Studies in Nonlinear Dynamics \& Econometrics, 17(5), 483.498. 
Mumtaz, H. and F. Zanetti (2013). The impact of the volatility of monetary policy shocks. Journal of Money, Credit and Banking 45, 535-558.

Mumtaz, H. and P. Surico (2013). Policy uncertainty and aggregate fluctuations. Queen Mary University of London, School of Economics and Finance, Working Paper No.708.

Mumtaz, H. and K. Theodoridis (2015). Common and country specific economic uncertainty. Queen Mary University of London, School of Economics and Finance, Working Paper No. 752.

Mumtaz, H., Sunder-Plassmann, L., and Theophilopoulou, A. (2016). The State Level Impact of Uncertainty Shocks, Queen Mary University of London, School of Economics and Finance, Working Paper No. 793.

Mumtaz, H. and K. Theodoridis (2016). The changing transmission of uncertainty shocks in the us: An empirical analysis. Journal of Business and Economic Statistics.

Nakata, T. (2013). Uncertainty at the Zero Lower Bound. Federal Reserve Board, Finance and Economics Discussion Series Working Paper No. 2013-09.

Orlik, A., and L. Veldkamp (2014). Understanding Uncertainty Shocks and the Role of Black Swans. NBER Working Paper No. 20445.

Rossi, B., and T. Sekhposyan (2015). Macroeconomic Uncertainty Indices Based on Nowcast and Forecast Error Distributions. American Economic Review Papers and Proceedings, 105(5), 650-655.

Rossi, B., T. Sekhposyan, and M. Soupre (2016). Understanding the sources of macroeconomic uncertainty. Mimeo, Universitat Pompeu Fabra - Centre de Recerca en Economia Internacional (CREI).

Schüler, Y. S. (2014). Asymmetric Effects of Uncertainty over the Business Cycle: A Quantile Structural Vector Autoregressive Approach. University of Konstanz, Department of Economics, Working Paper Series No. 2014-02.

Scotti, C. (2016). Surprise and Uncertainty Indexes: Real-Time Aggregation of Real-Activity Macro Surprises, Journal of Monetary Economics, vol. 82, pp. 1-19.

Segnon, M., Gupta, R., Bekiros, S., and Wohar, M.E. (2016). Forecasting US GNP Growth: The Role of Uncertainty. University of Pretoria, Department of Economics, Working Paper No. 201667.

Shin, M. and M. Zhong (2016). A new approach to identifying the real effects of uncertainty shocks. Finance and Economics Discussion Series 2016-040. Washington: Board of Governors of the Federal Reserve System.

Sin, C. Y. C. (2015). The economic fundamental and economic policy uncertainty of Mainland China and their impacts on Taiwan and Hong Kong. International Review of Economics \& Finance, 40(C), 298-311. 
Stock, J. H., and M. W. Watson (2012). Disentangling the Channels of the 2007-2009 Recession. Brookings Papers on Economic Activity, Spring, 81-135.

Stockhammar, P., and Österholm, P. (2016). Effects of US policy uncertainty on Swedish GDP growth. Empirical Economics, 50 (2), 443-462.

Strobel, J. (2015). On the different approaches of measuring uncertainty shocks. Economics Letters, 134, 69-72.

Wu, J. C., and Xia, F. D. (2016). Measuring the Macroeconomic Impact of Monetary Policy at the Zero Lower Bound. Journal of Money, Credit and Banking, 48, 2-3, 253-291. 
Figure 1. Impulse response of macroeconomic variables to structural shock of Euro area economic policy uncertainty under different output growth states $(\tau=.25,0.50,0.75)$ :

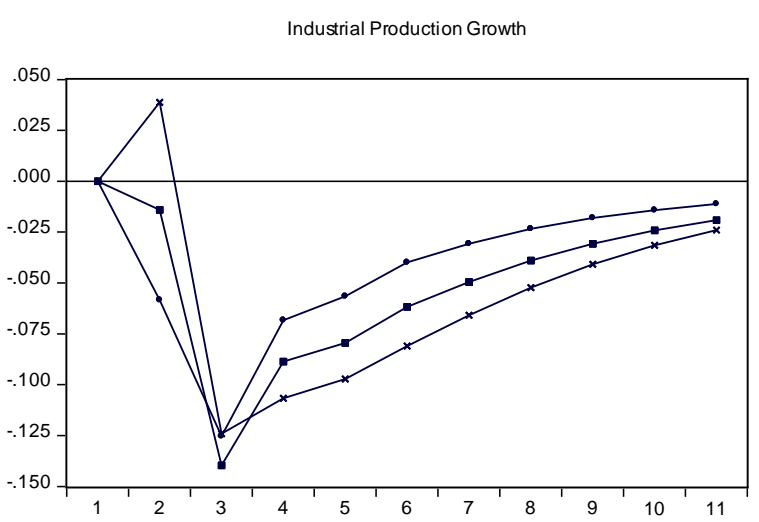

$\multimap 25 \% \multimap-50 \% \multimap 75 \%$

EA EPU

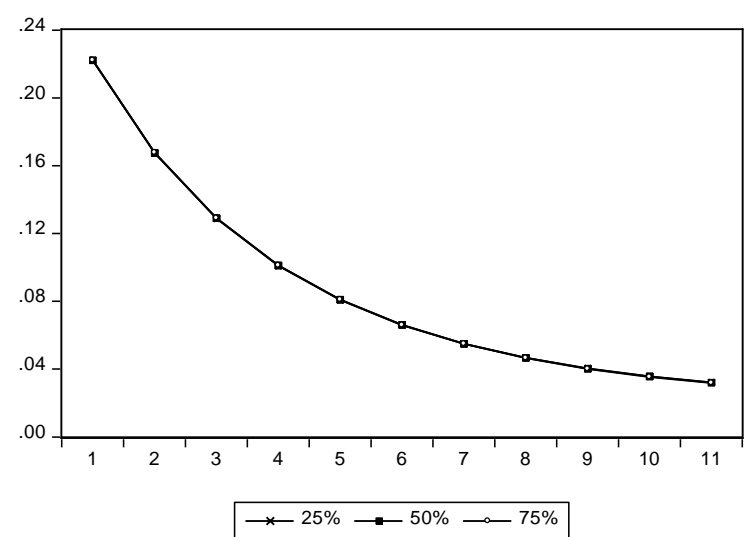

Interest Rate

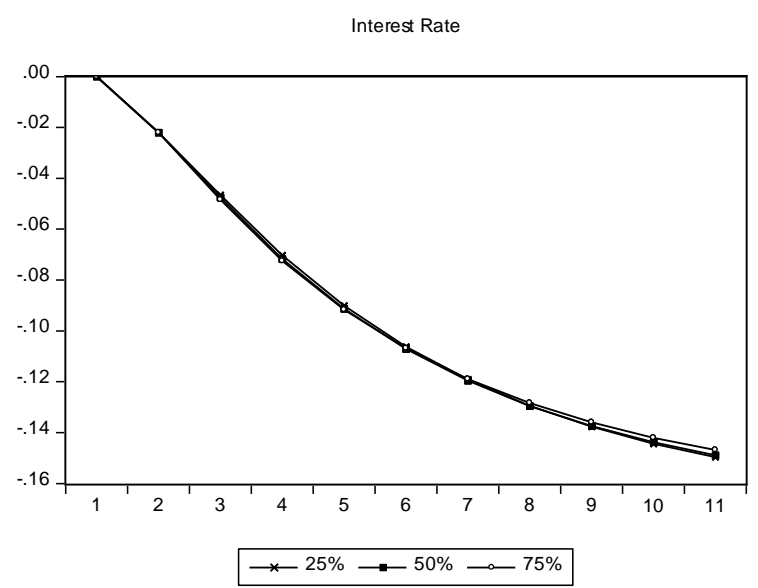

$\longrightarrow 25 \% \multimap-50 \% \multimap 75 \%$
Inflation

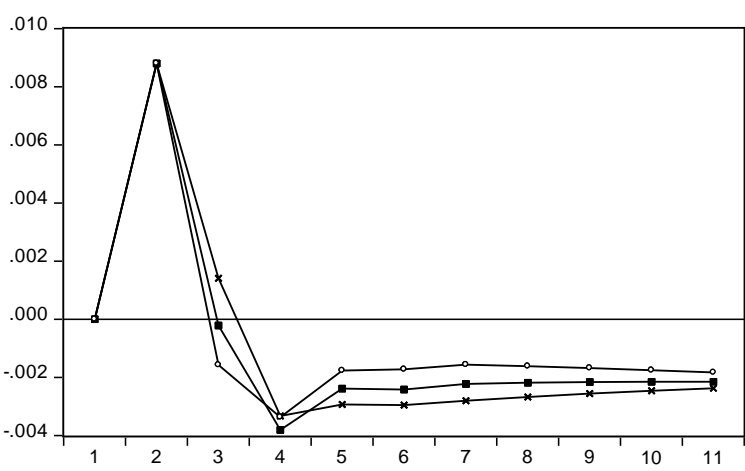

$\rightarrow-25 \% \multimap-50 \% \multimap 75 \%$

US EPU

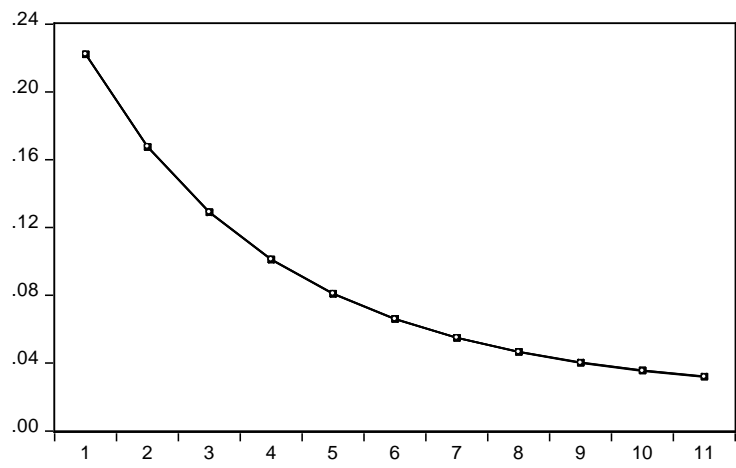

$\longrightarrow 25 \% \multimap-50 \% \multimap 75 \%$ 
Figure 2. Impulse response of macroeconomic variables to structural shock of US economic policy uncertainty under different output growth states $(\tau=0.25,0.50,0.75)$ :
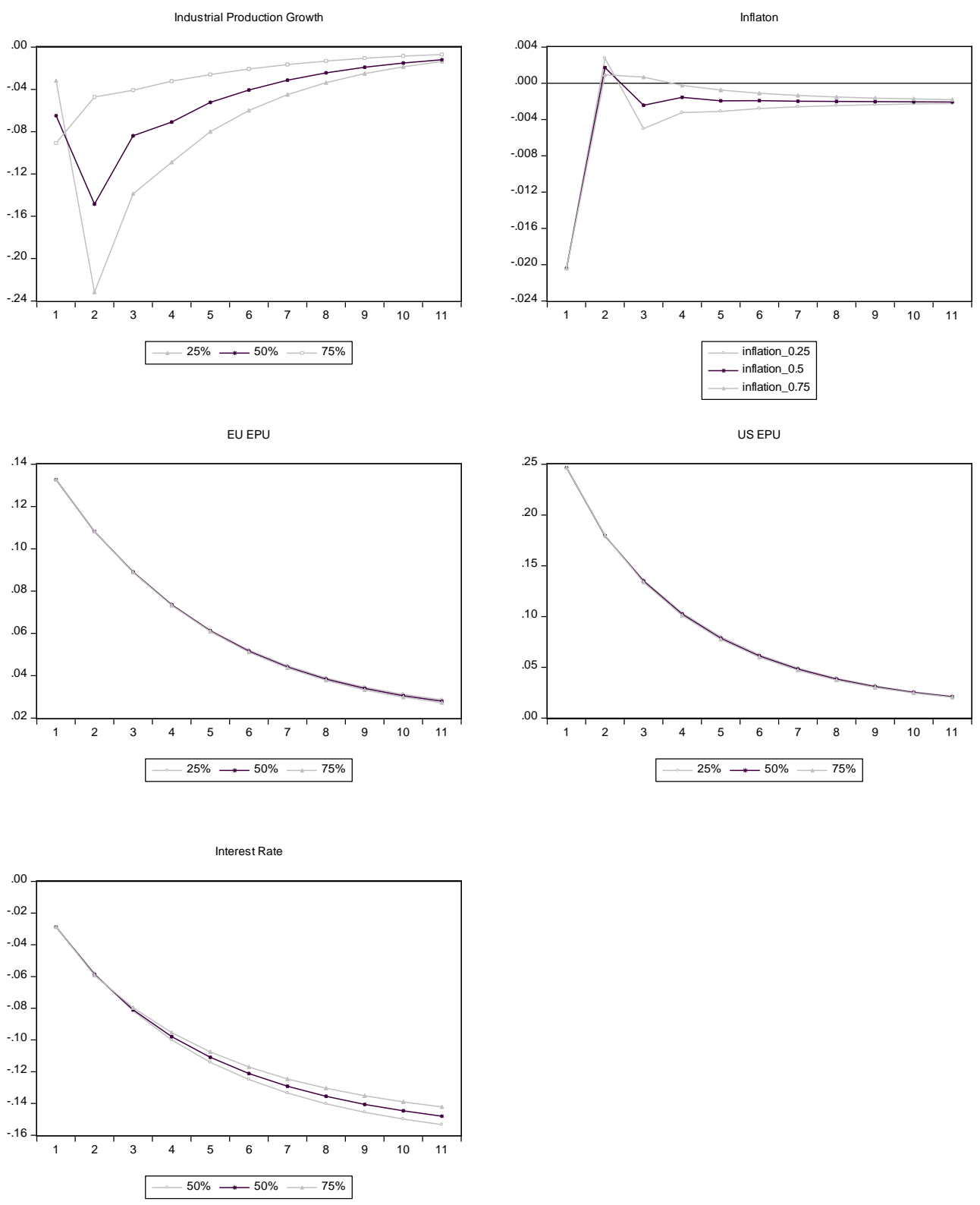
APPENDIX:

Figure A1. Impulse response of macroeconomic variables to structural shocks of US economic policy uncertainty under different output growth states $(\tau=0.25,0.50,0.75)$ :

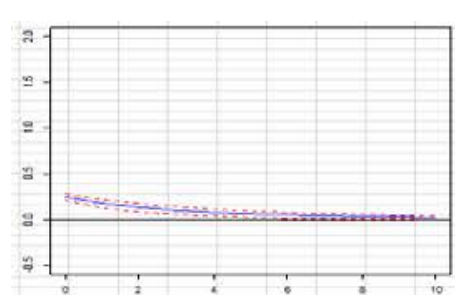

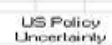

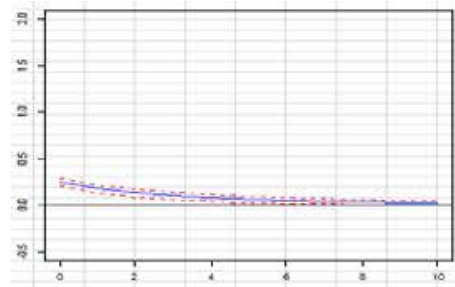

Us Policy,
uncertianity

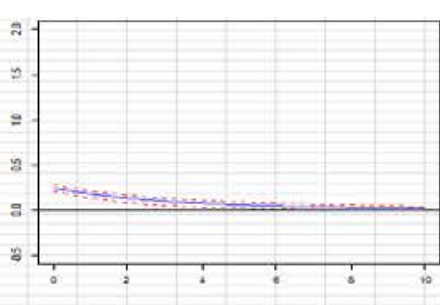

us policy

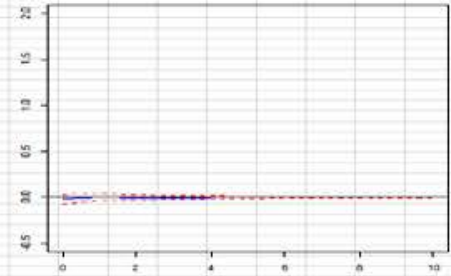

Initlation

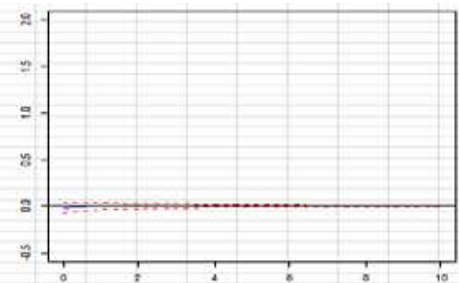

Intation

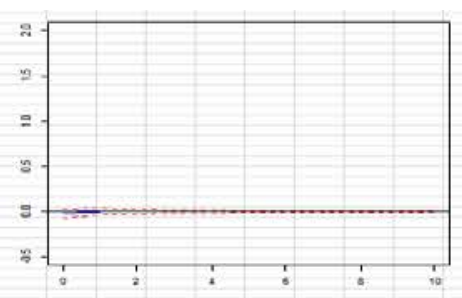

infroton

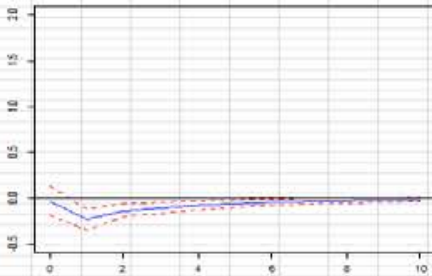

Duput Growath

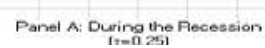

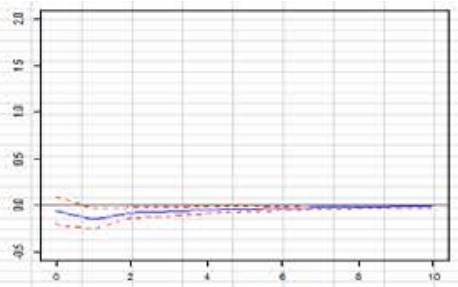

Duput Growith Ponel B During the general phasen

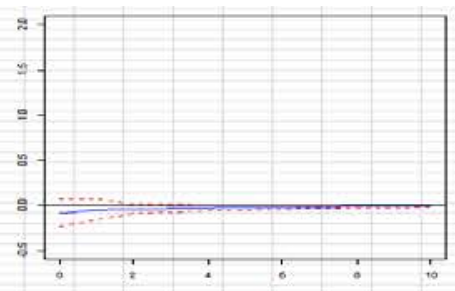

Outpun Growen

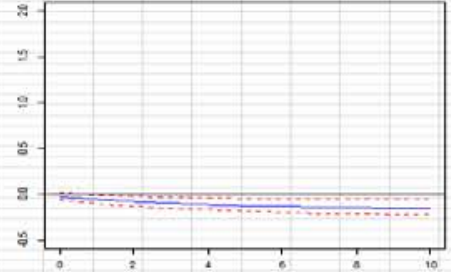

Internat far
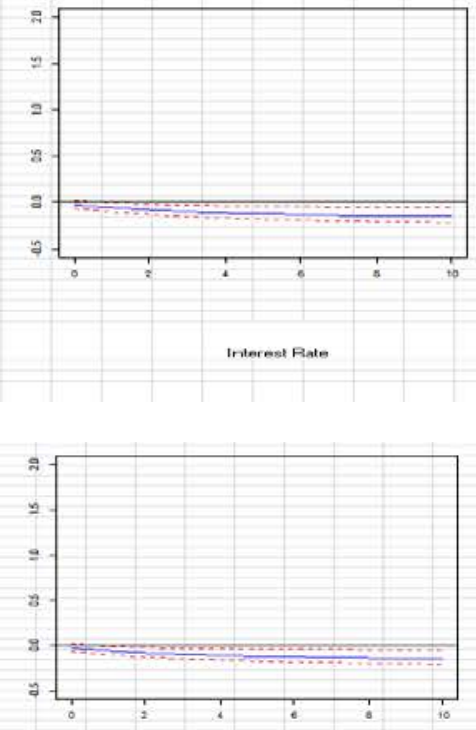

Interest Rate

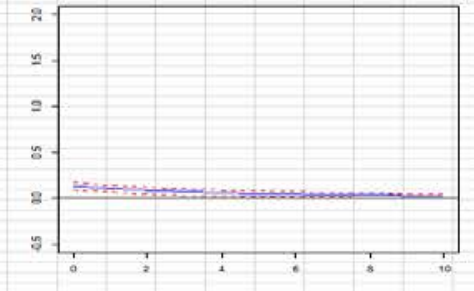

EA Polioy,
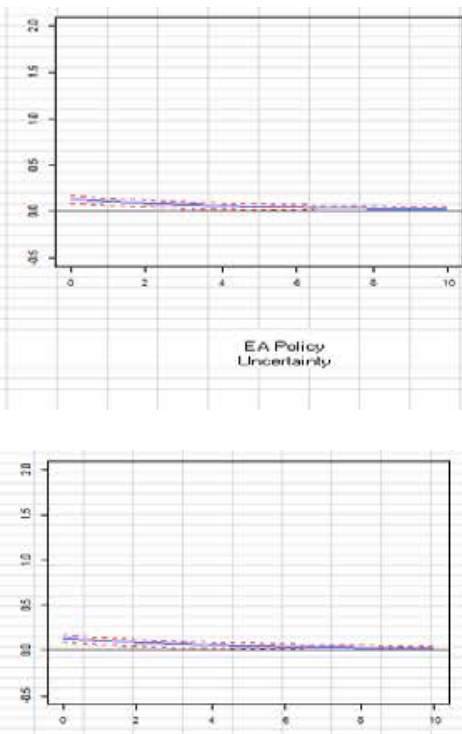

EUPolicy
Uncortiontey 